\title{
Plankton patchiness in the Polar Front region of the West Spitsbergen Shelf
}

\author{
Emilia Trudnowska*, Marta Gluchowska, Agnieszka Beszczynska-Möller, \\ Katarzyna Blachowiak-Samolyk, Slawomir Kwasniewski
}

Institute of Oceanology Polish Academy of Sciences, 81-712 Sopot, Poland

\begin{abstract}
Plankton patchiness, a widely known but poorly studied phenomenon, was investigated concurrently with measurements of environmental conditions in the Polar Front region west of Spitsbergen in summer (June-July) 2012. Continuous high-resolution observations were made using a laser optical plankton counter, a fluorometer and CTD along several sections in the surface $50 \mathrm{~m}$ of the sea with additional data from zooplankton net sampling and full-depth range hydrographical measurements at stations. The observed patches differed in terms of size, number and distribution patterns. They occupied only a minor portion of the studied ocean area $(2-17 \%)$, but contained plankton concentrations that were 3-17 times higher than the concentrations in the background waters. The generation and existence of patches was associated with particular conditions created by increased primary production, optimal hydrography, discontinuities in the density field and/or the presence of meanders or eddies. The distribution of small size fraction patches, consisting of the phytoplankton, inorganic particles and detritus, was closely related to specific patterns in hydrography. The medium-size zooplankton and marine snow were concentrated mainly in conjunction with discontinuities in density field. The distribution of the large copepods was independent of any oceanographic feature detected in this study, which points towards biological cues as factors regulating zooplankton aggregation processes. Diverse mechanisms of patch formation as well as their ecological significance are discussed in the context of planktonic responses to the structured environment in the region of the Polar Front.
\end{abstract}

KEY WORDS: Zooplankton · Patchiness · Zooplankton distribution - Laser optical plankton counter - Eddy · Polar Front · West Spitsbergen Current

${ }^{*}$ Corresponding author: emilia@iopan.gda.pl

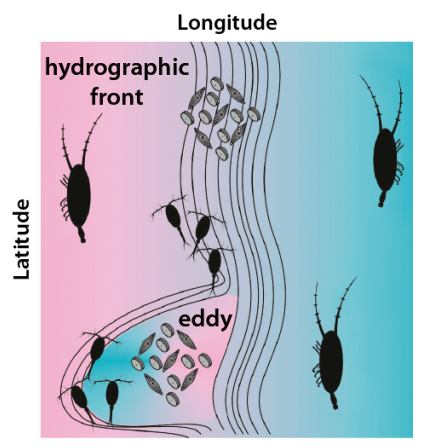

Horizontal

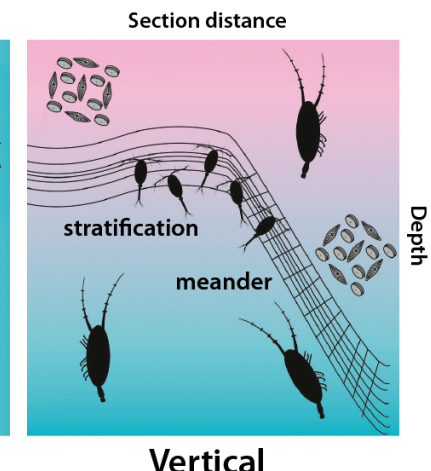

Vertical
Schematic plankton patchiness in Polar Front surface waters. Response of the size-fractionated plankton (small, medium, large) distribution patterns to a structured environment is presented in both horizontal (hydrographic front and eddy) and vertical (stratification and meander) planes.

Graphic: Emilia Trudnowska

\section{INTRODUCTION}

Plankton patchiness is a well-known phenomenon, although it is poorly characterized and understood (Haury et al. 1978, Franks 2005). Patchiness, or heterogeneity, is defined as a discontinuous distribution of individual organisms through space (Smith 1972) and is often a result of the interaction between physical and biological processes (Haury et al. 1978, Omori \& Hamner 1982, Folt \& Burns 1999). Plankton aggregations can arise as responses to temperature and salinity gradients or discontinuities, water motion, variation in light intensity, food and/or predator concentrations as well as from complex social and reproduction behaviours (Deutschman et al. 1993, Cowles \& Desiderio 1998, Ambler 2002). Patches can differ greatly in terms of their size, shape

() The authors 2016. Open Access under Creative Commons by Attribution Licence. Use, distribution and reproduction are unrestricted. Authors and original publication must be credited. 
and generative processes, their species- and sizespecific compositions, as well as the concentrations of individuals within aggregations (Omori \& Hamner 1982, Pinel-Alloul 1995, Folt \& Burns 1999). The role of patches in enhancing trophic transfer has been widely demonstrated (e.g. Wishner et al. 1988, Godø et al. 2012, Majaneva et al. 2013). Thus, spatial variability in the abundance of plankton is an essential theme in marine ecology.

There is a great variety of methodological approaches to adequately detect patchiness in zooplankton distribution, e.g. by net sampling (Wiebe 1970, Vogedes et al. 2014), continuous water pumping (Piontkovski et al. 1997, Molinero et al. 2008), acoustics (Zhou \& Huntley 1996, Genin et al. 2005), optical counters (Basedow et al. 2006, Trudnowska et al. 2012), video recording (Benfield et al. 1996, Davis et al. 2004), laboratory experiments (Dagg 1977) or modelling (Riley 1976, Woodson et al. 2005). Nevertheless, this phenomenon remains more a topic of speculation than one of actual measurements and documentation. When studying plankton distribution, one of the main challenges is achieving appropriate spatial resolution. This problem has been tackled in our study by the use of continuous and automatic measurements by an in situ laser optical plankton counter (LOPC), which has enabled the highresolution mapping of size-fractionated plankton together with simultaneous measurements of water mass characteristics. A further problem in patchiness studies arises from the lack of clear criteria to distinguish between a plankton patch and the ambient water. Among the existing approaches to define a patch, various thresholds have been applied (George 1981, Pinel-Alloul 1995, Dormann et al. 2007), such as the concentration of individuals exceeding the median value (Wiebe 1970, Mehlum et al. 1999); the local maximum, that is, a point in a data series at which the concentration of a particular category/type of particles and plankton exceeds the concentration at the preceding point by $30-50 \%$ (Gallager et al. 2004, Sullivan et al. 2010); and a density of individuals that is several orders of magnitude higher than the density at the remaining points from the observation series (Wiebe 1970, Wishner et al. 1988, Alldredge et al. 2002). There are also studies that have applied the Moran's I spatial autocorrelation coefficient (Kaltenberg \& Benoit-Bird 2013, Vogedes et al. 2014), which determines whether the studied elements of an ecosystem are dependent or independent of each other (Pinca \& Huntley 2000, Dormann et al. 2007, Molinero et al. 2008). An alternative to Moran's $I$ is the Mahalanobis generalized distance
$\left(D^{2}\right)$ coefficient, which allows the identification of observations far from the centre of the data cloud (Molinero et al. 2008). In the present study, following the approach used by Wiebe (1970) and Piontkovski et al. (1997), a patch was defined by data points in an observation series for which the abundance of plankton was $>1$ SD above the mean abundance recorded within the specified study area.

The ocean is highly structured, both horizontally and vertically, and this is most pronounced in coastal waters. Hence, shelf waters provide a patterned habitat in which the distribution of marine life is patchy on a range of scales (Woodson et al. 2005). The pelagic habitat on the West Spitsbergen Shelf (WSS) area is highly structured, mainly due to the interactions between water masses of Arctic and Atlantic origin associated with the presence of a pronounced hydrographic front. Moreover, the concurrence of steep horizontal gradients of temperature and density, along with barotropic and baroclinic instabilities that develop due to the presence of topographic discontinuities, results in the formation of diverse mesoscale water structures (e.g. meanders and eddies) (Nilsen et al. 2006, Teigen et al. 2010). Such ocean structures cause particle concentration and retention, and they enhance biological productivity (Franks 1992, Labat et al. 2009, Godø et al. 2012). The impact of such structures on phytoplankton has been clearly shown by remote sensing (e.g. Riandey et al. 2005, d'Ovidio et al. 2010), but their influence on zooplankton still needs to be assessed through in situ sampling, because zooplankton can exhibit much more fine-scale variation in their spatial distribution than phytoplankton (Levin 1992).

The convergence, mixing and exchange of the Atlantic- and Arctic-origin water masses on the WSS (Saloranta \& Svendsen 2001) results in a complex hydrography. On its offshore side, the West Spitsbergen Current (WSC) carries warm and saline Atlantic water into the Arctic Ocean (Saloranta \& Haugan 2001, Walczowski et al. 2005). The highest Atlantic water temperature and current speed are observed in the WSC core, which is confined to the upper part of the continental slope (BeszczyńskaMöller et al. 2012). The colder and fresher Arctictype water advected from Storfjorden around the southern tip of Spitsbergen is transported northward along the coast by the Sørkapp Current (SC). This current carries mainly Storfjorden surface water, which is a mixture of local meltwater that has been heated by solar radiation and Arctic water that has already been warmed in the shallow Barents Sea and advected into Storfjorden by the East Spitsbergen 
Current (Haarpaintner et al. 2001, Skogseth et al. 2005). Therefore, the Arctic-type water occupying the WSS is warmer and fresher than typical Arctic water (colder than $0^{\circ} \mathrm{C}$ and saltier than 34.8). The Arctic-type water carried over the shelf and the Atlantic water transported above the upper slope are typically separated by a frontal zone, which is a part of the larger-scale Polar Front system (Loeng 1991, Saloranta \& Svendsen 2001, Walczowski 2013). The Polar Front west of Spitsbergen is characterized by a density gradient only in the fresher surface water layer of approximately $50 \mathrm{~m}$, while beneath this layer, the front is density compensated and manifested through strong temperature and salinity gradients (Saloranta \& Svendsen 2001, Walczowski 2013).

The goal of this study was to investigate the phenomenon of plankton patchiness by the simultaneous detection of plankton patches and the environmental conditions under which they occur in the upper $50 \mathrm{~m}$ layer of the sea in the Polar Front region. The purpose was to find out whether particles and plankton accumulate within specific water masses or at characteristic discontinuity zones or whether they are formed irrespective of water mass structures. It was assumed that the distribution of particles and various plankton size fractions would differ because of their different mobility abilities. Our hypothesis was that small size fraction patches would be strongly related to the heterogeneity of the environment, whereas the patches of larger organisms would be more independent from the direct influence of the physical environment. By verifying the issues raised, we expected to provide new data for a discussion about the ecological significance of particles and plankton patchiness and their relation to physical features such as fronts and eddies.

\section{MATERIALS AND METHODS}

\section{Instrumentation and study design}

The distribution of particles, plankton and selected environmental variables was examined in summer 2012 within the frontal zone between the Arctic and Atlantic waters as well as along the sections in the core areas of these 2 domains in the area of the WSS (Fig. 1).

Continuous automatic measurements along sections were surveyed with the towed instrument platform carrying an LOPC (Brooke Ocean Technology), a conductivity-temperature-depth (CTD) sensor (SBE 911plus, Seabird Electronics) and a fluorometer (Seapoint Sensors). The details regarding the principles of the LOPC are presented elsewhere (e.g. Herman et al. 2004, Basedow et al. 2010, Trudnowska et al. 2014). The LOPC detects particles and plankton in a size range from 0.1 to $35.0 \mathrm{~mm}$ equivalent spherical diameter (ESD), which will henceforth be referred to as the size range of the total abundance. The LOPC counts were first integrated into 50 consecutive size classes, equally spaced along a $\log _{10}$ axis, and then re-grouped into 3 size fractions: small (S: $0.1-0.3 \mathrm{~mm}$ ESD), medium (M: 0.3-0.8 mm ESD) and large (L: $0.8-5.0 \mathrm{~mm}$ ESD). The measurements of the smallest size fractions $(<0.25,<0.3$ or $<0.5 \mathrm{~mm}$ ESD) are often neglected in zooplankton studies at high latitudes (Basedow et al. 2010, Trudnowska et al. 2012,2014 ) because they theoretically include phytoplankton aggregations, marine snow or suspended matter from glaciers, sea ice or sea bed sediments. In this study, however, this smallest size fraction (S) was also included in the analyses as a real and potentially important constituent of the pelagic ecosystem. The
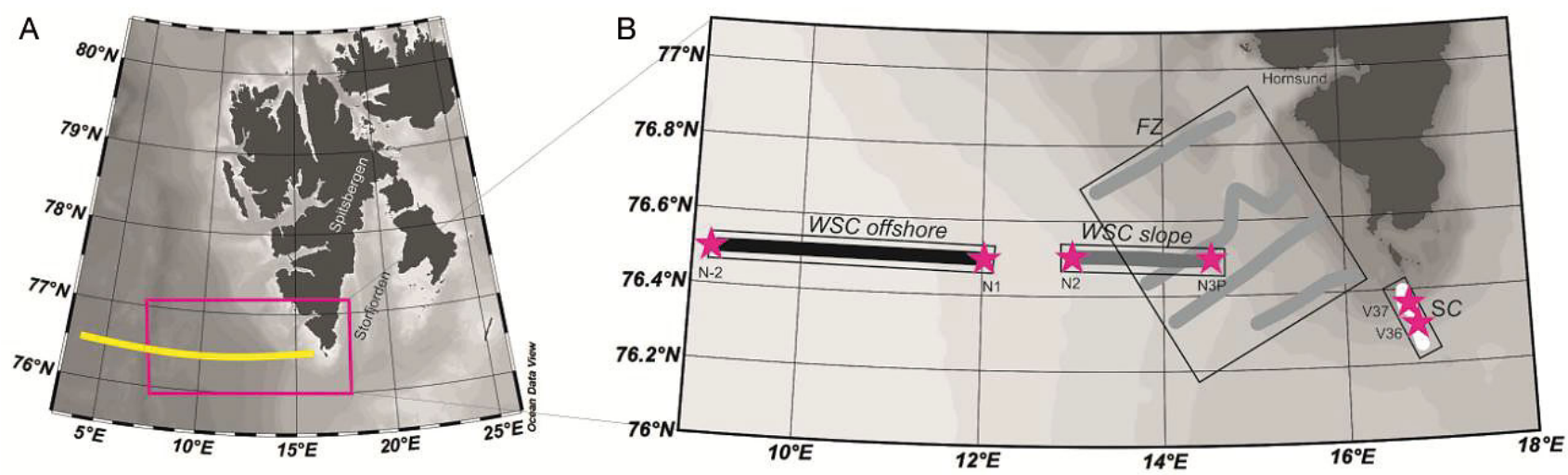

Fig. 1. Study area. (A) Svalbard archipelago with the West Spitsbergen Shelf region. Pink rectangle indicates the area of the laser optical plankton counter (LOPC) surveys; yellow line indicates the route of the full-depth hydrographic stations. (B) Survey area. Grey, black and white lines indicate routes of the individual LOPC-CTD-fluorometer sections; pink stars indicate net sampling stations. FZ: frontal zone; SC: Sørkapp Current; WSC: West Spitsbergen Current 
larger size fractions ( $\mathrm{M}$ and $\mathrm{L}$ ) represent mainly mesozooplankton, for which LOPC is well suited, and consist of medium-sized zooplankton such as Oithona, Triconia, Microcalanus and nauplii copepods, and various benthic larvae as well as largesized Pseudocalanus, Metridia and Calanus copepods. The occasional counts of macrozooplankton, i.e. organisms $>5.0 \mathrm{~mm}$ ESD (euphausiids, amphipods), were included in the total abundance calculations.

In the frontal zone area (FZ sections), the continuous automatic measurements were made along 4 sections at a constant depth of approximately $25 \mathrm{~m}$ (Table 1, Fig. 1). In the SC, WSC slope and WSC offshore sections, the measurements were performed in an undulating mode, spanning the layer from the subsurface (approximately $2 \mathrm{~m}$ ) down to $50 \mathrm{~m}$ depth. The SC section ( $20 \mathrm{~km}$ long) across the southernmost part of the Spitsbergen shelf was set in the area of Arctic-type water inflow onto the WSS. The WSC slope ( 40 km long) and offshore ( 70 km long) sections were set in the Atlantic WSC water flow.

\section{Data processing and statistics}

LOPC counts were divided by the volume of the water passing through the sampling tunnel and were averaged horizontally over $5 \mathrm{~m}$ distance intervals for constant-depth horizontal tows (FZ sections) and vertically over $1 \mathrm{~m}$ depth intervals for the undulating sampling mode tows (SC and WSC sections). The counts that exceeded the mean abundance by $>1$ SD in the selected size categories ( $\mathrm{S}, \mathrm{M}$ or $\mathrm{L})$ were interpreted as counts of the particle and/or plankton patches (Wiebe 1970, Piontkovski et al. 1997), whereas the remaining lower abundance counts were regarded as background (Wiebe 1970). The threshold values of particle and plankton abundance used to discriminate between a patch and the background were established individually for each section (FZ, SC, WSC slope and WSC offshore). A dedicated MATLAB programme was employed to calculate, detect and extract all patches and background water measurements that met these criteria.

To analyse the relationships between plankton distribution and hydrography, each variable was interpolated using a Kriging routine (Surfer 8.0, Golden Software) in $1 \mathrm{~m}$ vertical and $0.5 \mathrm{~km}$ horizontal distance gridding. The standardized anomalies of the plankton abundances and environmental parameters were calculated by subtracting the horizontal sample average and dividing it by the corresponding sample standard deviation. Non-parametric Spearman's rankorder correlations (Sokal \& Rohlf 1981; Statistica 10.0, StatSoft) were used to test the pairwise relationships between vertically averaged (over each separate depth profile) zooplankton abundances in the selected size categories (S, M, L) and environmental variables (temperature, salinity, density, chlorophyll fluorescence).

Seawater density was calculated from salinity, temperature and pressure using the MATLAB seawater toolbox (http://mooring.ucsd.edu/software/matlab/ doc/toolbox/ocean/swstate.html). Chlorophyll a concentration was determined fluorometrically by an in situ sensor. The Ocean Data View software programme (Schlitzer 2015) was used to prepare figures.

In addition to the high-resolution particle and plankton distribution measurements, full-depth hydrographic measurements were performed at fixed stations along the section crossing the WSC at $76^{\circ} 30^{\prime} \mathrm{N}$.

Table 1. Sections and stations, sampling dates, times, locations and bottom depths. FZ: frontal zone; LOPC: laser optical plankton counter; SC: Sørkapp Current; WSC: West Spitsbergen Current

\begin{tabular}{|c|c|c|c|c|c|c|c|}
\hline LOPC section & Net station & & Date & Time (UTC) & Latitude & Longitude & Bottom depth (m) \\
\hline \multirow[t]{2}{*}{ FZ } & & Start & 27.07 .2012 & $16: 00$ & $76^{\circ} 26.91^{\prime} \mathrm{N}$ & $016^{\circ} 05.56^{\prime} \mathrm{E}$ & \\
\hline & & End & 29.07 .2012 & $16: 20$ & $76^{\circ} 51.62^{\prime} \mathrm{N}$ & $014^{\circ} 42.18^{\prime} \mathrm{E}$ & \\
\hline \multirow[t]{4}{*}{$\mathrm{SC}$} & & Start & 29.06.2012 & $02: 42$ & $76^{\circ} 15.07^{\prime} \mathrm{N}$ & $016^{\circ} 50.18^{\prime} \mathrm{E}$ & \\
\hline & V36 & & & $03: 43$ & $76^{\circ} 18.94^{\prime} \mathrm{N}$ & $016^{\circ} 47.03^{\prime} \mathrm{E}$ & 106 \\
\hline & V37 & & & $04: 50$ & $76^{\circ} 20.81^{\prime} \mathrm{N}$ & $016^{\circ} 44.18^{\prime} \mathrm{E}$ & 110 \\
\hline & & End & 29.06 .2012 & $06: 12$ & $76^{\circ} 23.81^{\prime} \mathrm{N}$ & $016^{\circ} 38.38^{\prime} \mathrm{E}$ & \\
\hline \multirow[t]{2}{*}{ WSC slope } & N3P & Start & 11.07 .2012 & 01:25 & $76^{\circ} 29.83^{\prime} \mathrm{N}$ & $014^{\circ} 31.50^{\prime} \mathrm{E}$ & 212 \\
\hline & N2 & End & 11.07 .2012 & $08: 55$ & $76^{\circ} 30.00^{\prime} \mathrm{N}$ & $013^{\circ} 03.86^{\prime} \mathrm{E}$ & 1519 \\
\hline \multirow[t]{2}{*}{ WSC offshore } & N1 & Start & 11.07 .2012 & $19: 26$ & $76^{\circ} 29.92^{\prime} \mathrm{N}$ & $011^{\circ} 59.04^{\prime} \mathrm{E}$ & 1888 \\
\hline & $\mathrm{N}-2$ & End & 12.07 .2012 & 09:12 & $76^{\circ} 30.19^{\prime} \mathrm{N}$ & $009^{\circ} 04.54^{\prime} \mathrm{E}$ & 2250 \\
\hline
\end{tabular}


Hydrographic data were collected using a SeaBird SBE911plus CTD, equipped with duplicate temperature and conductivity sensors. The data were processed in a standard manner (Walczowski 2013).

\section{Zooplankton net samples}

Continuous measurements of the plankton distribution were supplemented with zooplankton net samples collected at stations located in the SC, WSC slope and WSC offshore sections (Table 1, Fig. 1). The zooplankton samples were collected in vertically stratified net hauls (from 2 to 5 layers distinguished within the upper $50 \mathrm{~m}$ ), made with a Multiple Plankton Sampler (MPS; Hydro-Bios) or WP2 net, both equipped with net bags of $180 \mu \mathrm{m}$ mesh size. Net samples were preserved in a $4 \%$ formaldehyde-in-seawater solution buffered with borax. In the laboratory, the zooplankton samples were examined for taxonomic composition and abundance following the protocols described in Postel (2000). First, large organisms $(>5.0 \mathrm{~mm})$ were picked out, identified and counted. The remaining zooplankton were suspended in a fixed volume of water, from which $2 \mathrm{ml}$ subsamples were taken with a large-volume automatic pipette, and examined thoroughly under a stereomicroscope. The number of subsamples was determined individually such that at least 500 individuals per sample were identified and counted. At the end, the remaining volume of the sample was scanned to find and identify taxa that had not been found previously. Zooplankton organisms were identified to species or the lowest taxonomic level possible, including, where feasible, identification of the developmental stages. Calanus species were identified based on morphology and size according to criteria from Kwasniewski et al. (2003). Zooplankton abundance was expressed as the number of individuals in a cubic metre (ind. $\mathrm{m}^{-3}$ ) of seawater.

\section{RESULTS}

\section{Frontal zone sections}

The water temperature, salinity, density and chlorophyll fluorescence, as well as the particles and plankton concentrations at the $25 \mathrm{~m}$ depth in the FZ sections, were higher in the Atlantic than in the Arctic water domain (Fig. 2).

Patches of the small size fraction were located mainly near the front along the whole investigated area $(55 \mathrm{~km}$, the distance between the southern and northern sections) and extended for ca. $2-5 \mathrm{~km}$. A few patches of the medium and large size fractions were observed adjacent to the hydrographic front, while others were located farther out. They typically extended for a few kilometres along the survey route and continued in the parallel sections, suggesting they could reach more than $15 \mathrm{~km}$ in length. The mean concentrations of particles and plankton estimated within the patches in the FZ sections were 3.5 (S), $7.5(\mathrm{M})$ and $16.7(\mathrm{~L})$ times higher than within the background waters (Table 2).
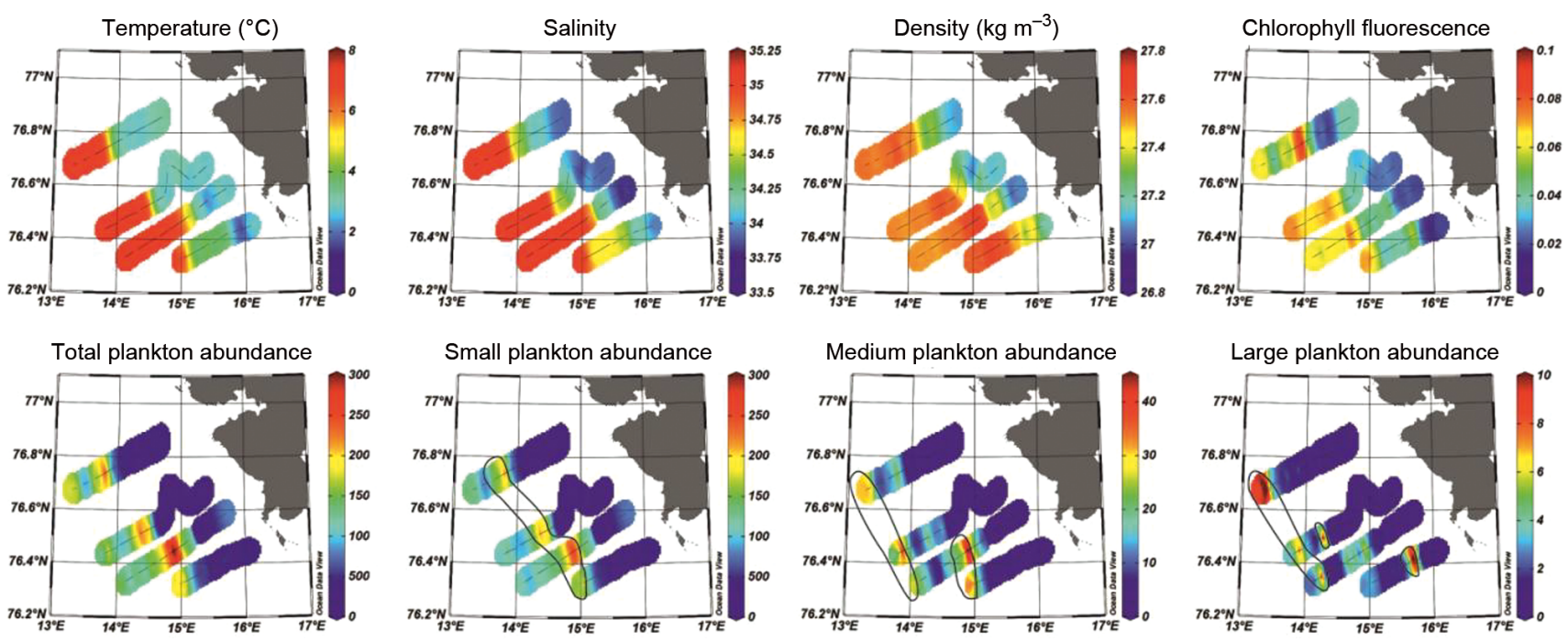

Fig. 2. Frontal zone (FZ) sections, approximately $25 \mathrm{~m}$ depth. Top: Distribution of temperature, salinity, density and chlorophyll fluorescence along the FZ sections. Bottom: Abundances (ind. $\left.\mathrm{m}^{-3} \times 10^{3}\right)$ of total $(0.1-35 \mathrm{~mm}$ equivalent spherical diameter [ESD]), small (0.1-0.3 mm ESD), medium (0.3-0.8 mm ESD) and large (0.8-5.0 mm ESD) size fractions along the FZ sections. The identified patches are outlined by solid black lines 


\section{Sørkapp Current section}

The upper $50 \mathrm{~m}$ layer in the SC section was stratified. The surface 10-20 m was occupied by warm and fresh waters, exhibiting a signature of local meltwater, while the layer underneath contained cold and more saline waters, most likely originating from the East Spitsbergen Current (Fig. 3). Elevated values of chlorophyll fluorescence and a higher total abundance of particles and plankton in the SC section were found generally in the cold lower layer.

The patches of the small and medium size fractions were mainly distributed in the lower, cold-water part of the SC section. They had a horizontal dimension of a few kilometres and a vertical dimension ranging from a few metres to $10 \mathrm{~m}$. Additionally, one pronounced abundance peak, formed mainly by small size particles, was registered in the northern shallow part of the section (Fig. 3). The patches of the large fraction were found in the lower layer, in water pockets with high chlorophyll fluorescence, or in the upper $10 \mathrm{~m}$ layer in waters characterized by low salinity, density and chlorophyll fluorescence. They were, on average, $5 \mathrm{~km}$ in the horizontal dimension and varied between a few and more than $20 \mathrm{~m}$ in the vertical dimension. The mean concentrations of particles and plankton estimated within the patches in the SC section were $4.8(\mathrm{~S}), 6.3(\mathrm{M})$ and $3.4(\mathrm{~L})$ times higher than in the background waters (Table 2).

\section{WSC slope section}

Two distinct hydrographic structures were observed in the WSC slope section (Fig. 4). One was a small but pronounced intrusion of colder and less saline water, found in the middle portion of the section, occupying the entire $45 \mathrm{~m}$ span of the studied layer. The other was a doming of denser water with lower temperature observed on the western side of the section. A similar, albeit smaller, upward shift of denser and colder water was recognized in the

Table 2. Mean abundance (ind. $\mathrm{m}^{-3} \times 10^{3}$ ) of particles and plankton within the patches of small (S), medium (M) and large (L) size fractions and background (Bgr.) waters of different sections studied (see Fig. 1)

\begin{tabular}{|lrrrrrrrr|}
\hline \multirow{2}{*}{$\begin{array}{l}\text { Size } \\
\text { fraction }\end{array}$} & \multicolumn{2}{c}{ FZ } & \multicolumn{2}{c}{ SC } & \multicolumn{2}{c|}{ WSC slope } & \multicolumn{2}{c|}{ WSC offshore } \\
& Patch & Bgr. & Patch & Bgr. & Patch & Bgr. & Patch & Bgr. \\
\hline S & 212.0 & 61.1 & 192.2 & 40.3 & 552.2 & 171.9 & 187.1 & 69.9 \\
M & 41.5 & 5.5 & 44.4 & 7.0 & 116.9 & 30.2 & 27.0 & 2.7 \\
L & 14.6 & 0.9 & 2.4 & 0.7 & 8.1 & 1.5 & 3.5 & 0.2 \\
\hline
\end{tabular}

eastern part of the section. Full-depth hydrographic measurements at the fixed stations revealed the presence of an anticyclonic mesoscale baroclinic eddy with a diameter of approximately $30-40 \mathrm{~km}$ and a vertical extent of approximately $700 \mathrm{~m}$ (Fig. 5). The eddy was characterized by a warm and salty core and occupied most of the WSC slope section. The western intrusion found in the WSC slope section coincided with the western edge of the observed eddy structure, while the colder and fresher eastern intrusion was enclosed within the eddy.

Very high chlorophyll fluorescence was measured inside the eddy structure between the cold intrusion and the doming structure, and it was associated with extremely high total particle and plankton abundance. Most of the observed patches in the selected size categories (S, M, L) extended vertically throughout the entire $50 \mathrm{~m}$ layer and spread horizontally from $2 \mathrm{~km}$ up to $11 \mathrm{~km}$. The conspicuous aggregations of the medium and large size fractions clung to the peripheries of the observed hydrographic structures (Figs. 4 \& 6). In addition, a few other patches of the large size fraction with various spatial dimensions were dispersed regularly along the entire WSC slope section. The mean abundances of particles and plankton within the patches were $3.2(\mathrm{~S}), 3.9(\mathrm{M})$ and 5.4 (L) times higher than in the background waters (Table 2).

\section{WSC offshore section}

The water in the eastern part of the WSC offshore section was warmer and more saline than in the western part (Fig. 6). The hydrographic measurements made over the full depth range along this section (Fig. 5) suggest that the elevated temperature and salinity in the eastern part of the WSC offshore section may have resulted from the presence of shallow meanders or a very weak eddy in the upper 40-50 m layer filled with the Atlantic water from the WSC core flowing over the slope.

The vertical distribution of chlorophyll fluorescence along the WSC offshore section was relatively uniform, with peak values at 10-30 m depth. Horizontally, however, the chlorophyll fluorescence values decreased towards the centres of the southward flow of the supposed meanders. Large and pronounced patches of the small size fraction were observed in the upper part of the studied water column in the WSC offshore section, extend- 

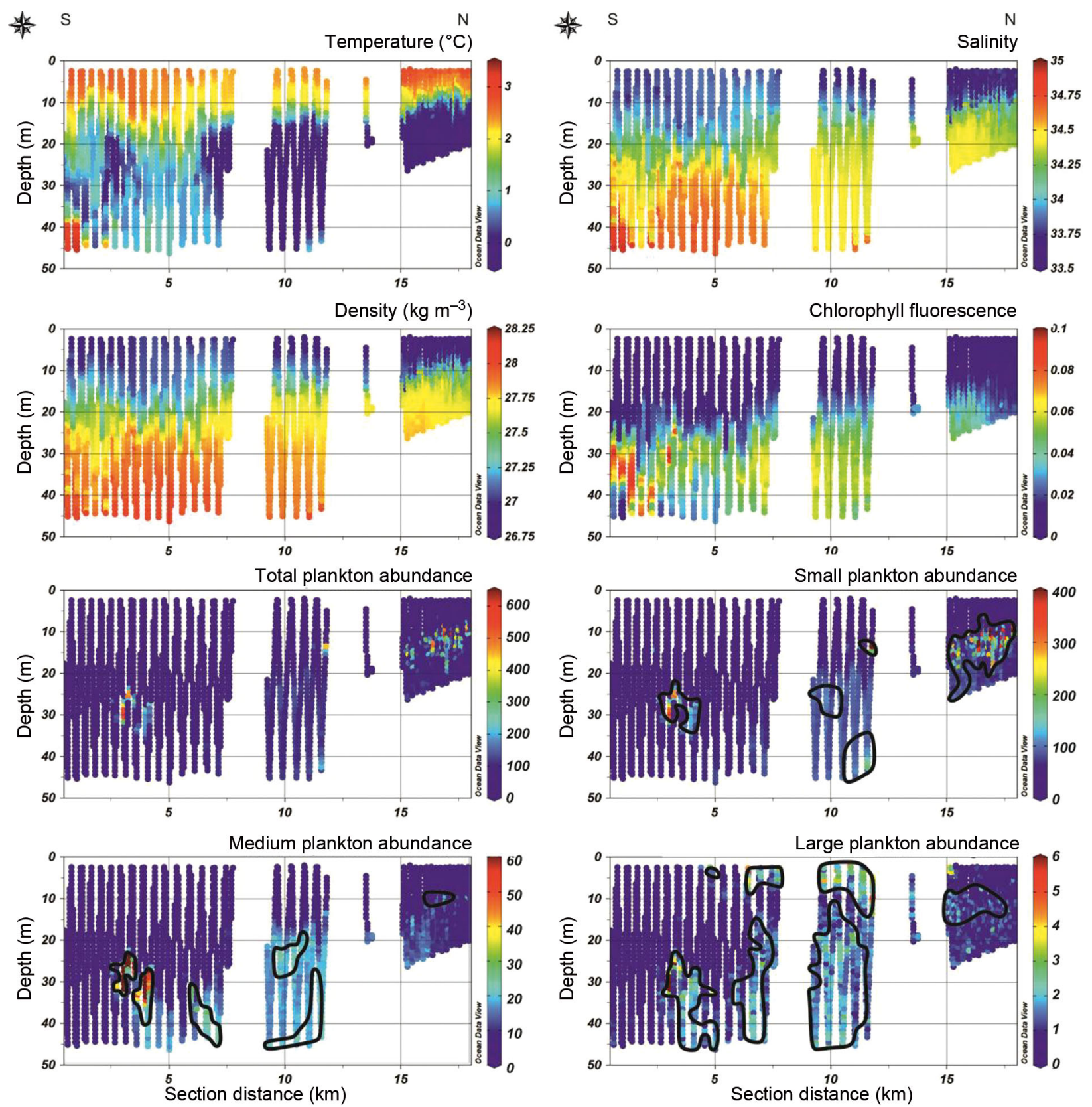

Fig. 3. Sørkapp Current (SC) section. Distribution of temperature, salinity, density, chlorophyll fluorescence and plankton abundance (ind. $\mathrm{m}^{-3} \times 10^{3}$ ) of total, small, medium and large size fractions along the section. The identified patches are outlined by solid black lines

ing vertically down to $30 \mathrm{~m}$ and coinciding with the eastern warm branch of the meander. The medium size fraction patches extended vertically for at least $20 \mathrm{~m}$ and were relatively narrow in the horizontal plane. They were found in the western part of the section, at the periphery of a pocket of denser, slightly colder and more saline water, which was assumed to be associated with sloping isopycnals and a wedge-shaped Atlantic water layer in the WSC offshore branch. The numerous patches of the large plankton were not associated with any of the hydrographic features. They concentrated mainly within the upper $10 \mathrm{~m}$ layer in the eastern part and within the upper $30 \mathrm{~m}$ layer in the western part of the WSC offshore section. The mean concentrations of particles and plankton found within the patches were $2.7(\mathrm{~S}), 9.0(\mathrm{M})$ and $17.5(\mathrm{~L})$ times higher than the concentrations in the background waters (Table 2). 

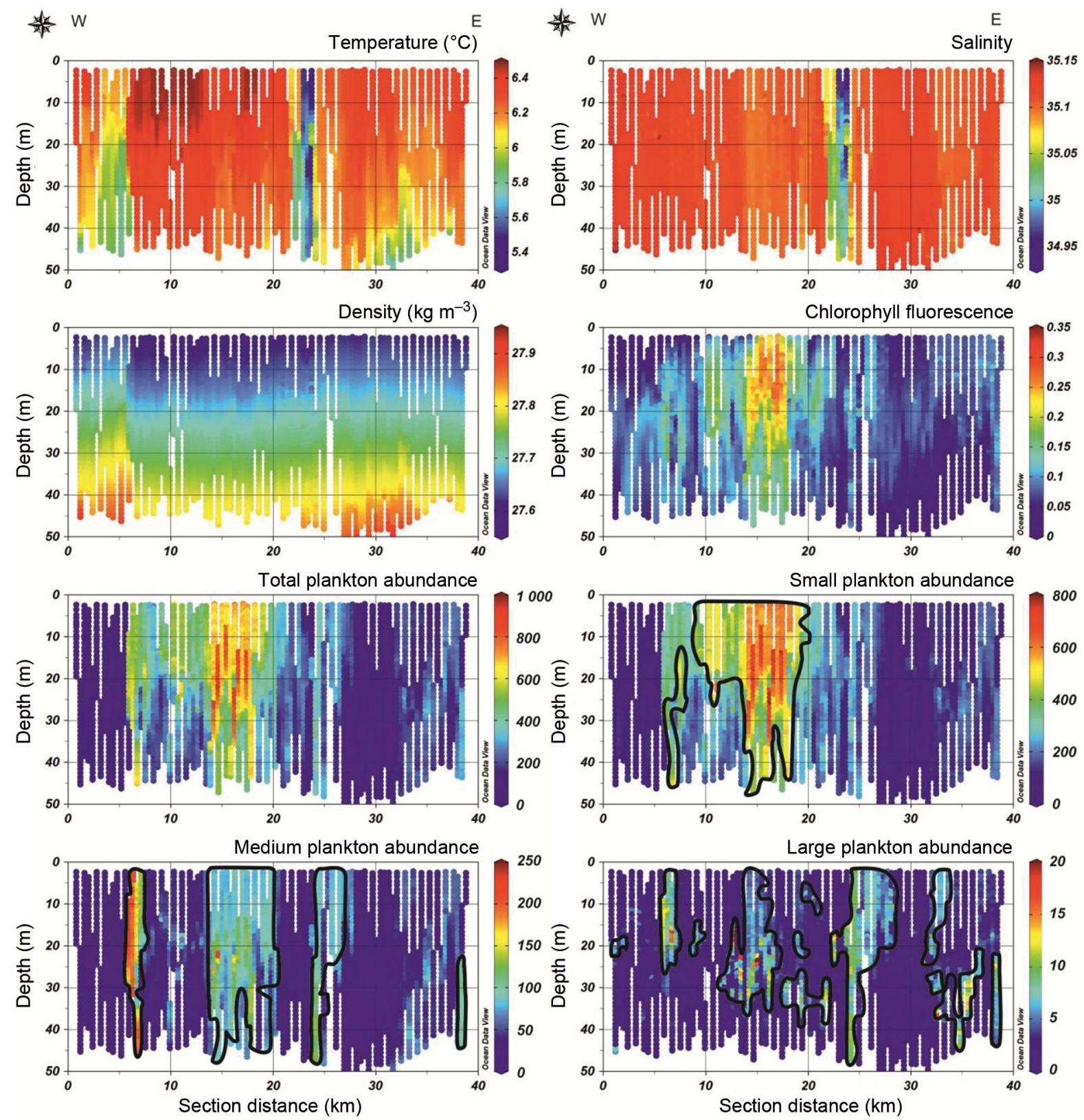

Fig. 4. West Spitsbergen Current (WSC) slope section. Distribution of temperature, salinity, density, chlorophyll fluorescence and plankton abundance (ind. $\mathrm{m}^{-3} \times 10^{3}$ ) of total, small, medium and large size fractions along the section. The identified patches are outlined by solid black lines

\section{Relationships with water characteristics and discontinuities}

The correlations between vertically averaged zooplankton abundances in the selected size categories $(\mathrm{S}, \mathrm{M}, \mathrm{L})$ and the environmental variables (temperature, salinity, density, chlorophyll fluorescence) were analysed to verify whether there are statistical relationships between the observed patchiness patterns and the water characteristics (Table 3).
The abundance and distribution of the small size fraction was highly correlated with all measured characteristics of the water masses (temperature, salinity, density and chlorophyll fluorescence). In particular, a strong correlation was found between the abundance of small particles and water density (positive trend in FZ and SC sections and negative in both WSC sections). The strongest correlations between the abundance of the medium size fraction and the environmental variables were found in the 


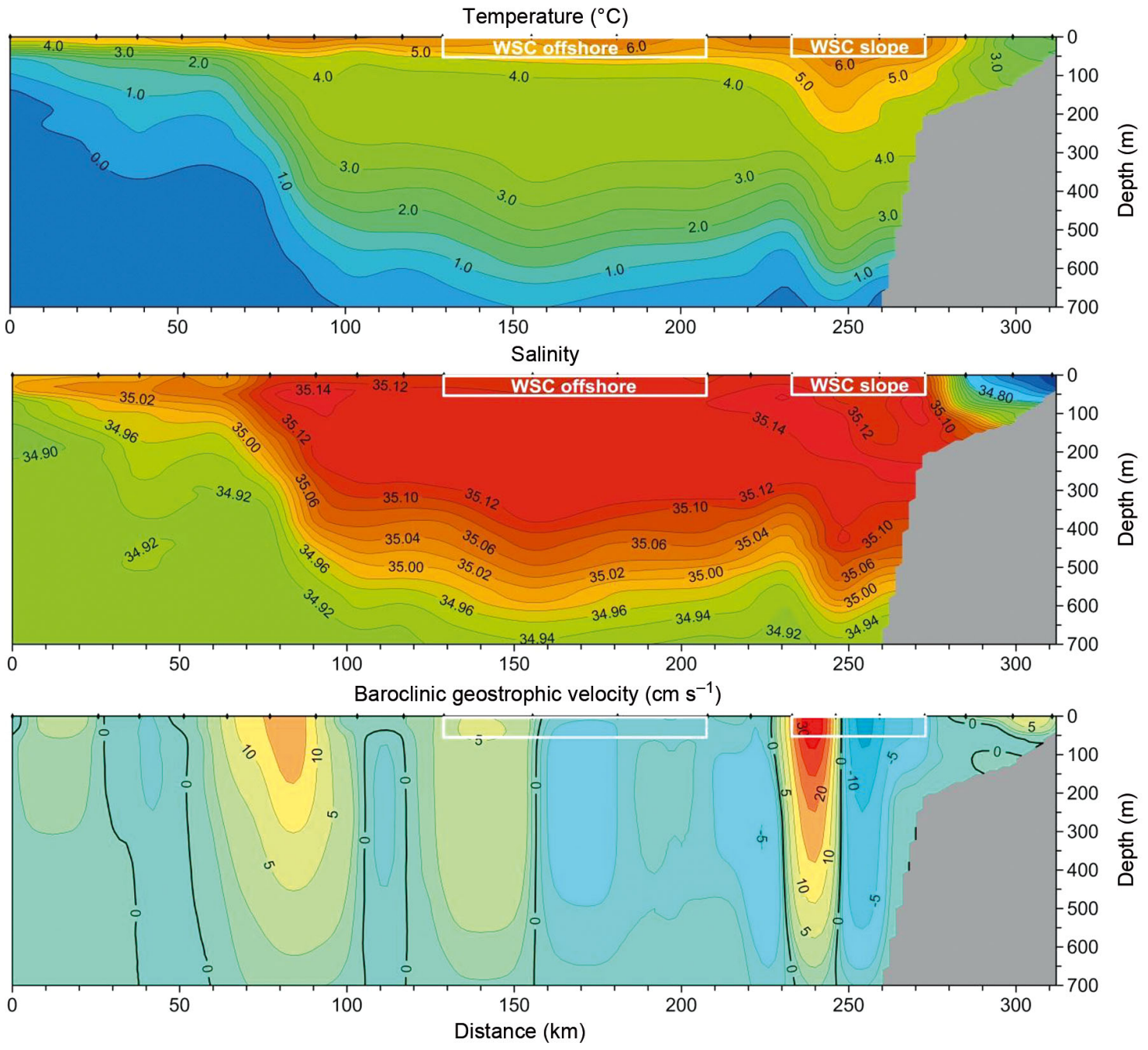

Fig. 5. Distribution of temperature, salinity and baroclinic geostrophic velocity in the upper $700 \mathrm{~m}$ layer. The locations of the West Spitsbergen Current (WSC) slope and WSC offshore laser optical plankton counter (LOPC) sections are indicated by white rectangles

sections in which large hydrographic gradients were observed (FZ and WSC slope sections). The correlations between the large size zooplankton abundance and the environmental variables were generally weak, except for in the SC and FZ sections.

The distribution of anomalies from average values over distance for individual sections, for particle and plankton abundance, and for the measured environmental variables showed a correlation between the occurrence of the peak abundance anomalies and the positions of the supposed water structures, such as increased pelagic system productivity (chlorophyll distribution) and water mass dynamics (hydrographical fronts, eddies or meanders). The largest anomalies in the distribution of all measured variables were observed in the FZ region, where the positive anomalies of particle and plankton abundance were located mainly in the Atlantic water domain near the front (Fig. 7). In the SC section, higher-than-average abundances of all size fractions $(S, M, L)$ coincided with higher-than-average salinity, density and chlorophyll and lower-than-average temperature (Fig. 7). In the southern part of the SC section $(0-12 \mathrm{~km})$, the abundance of small size fraction particles was positively correlated with chlorophyll fluorescence, while in the northern shallow part of the section, this correlation was negative. In the WSC slope and offshore sections, a strong, negative relationship was recorded between the anomalies of small size fraction abundance and water density. In the WSC slope section, positive abundance anomalies of the medium and, to some extent, large size fractions were observed close to the eastern edges of the 2 most pronounced temperature anomalies. Relationships between the anomalies of 

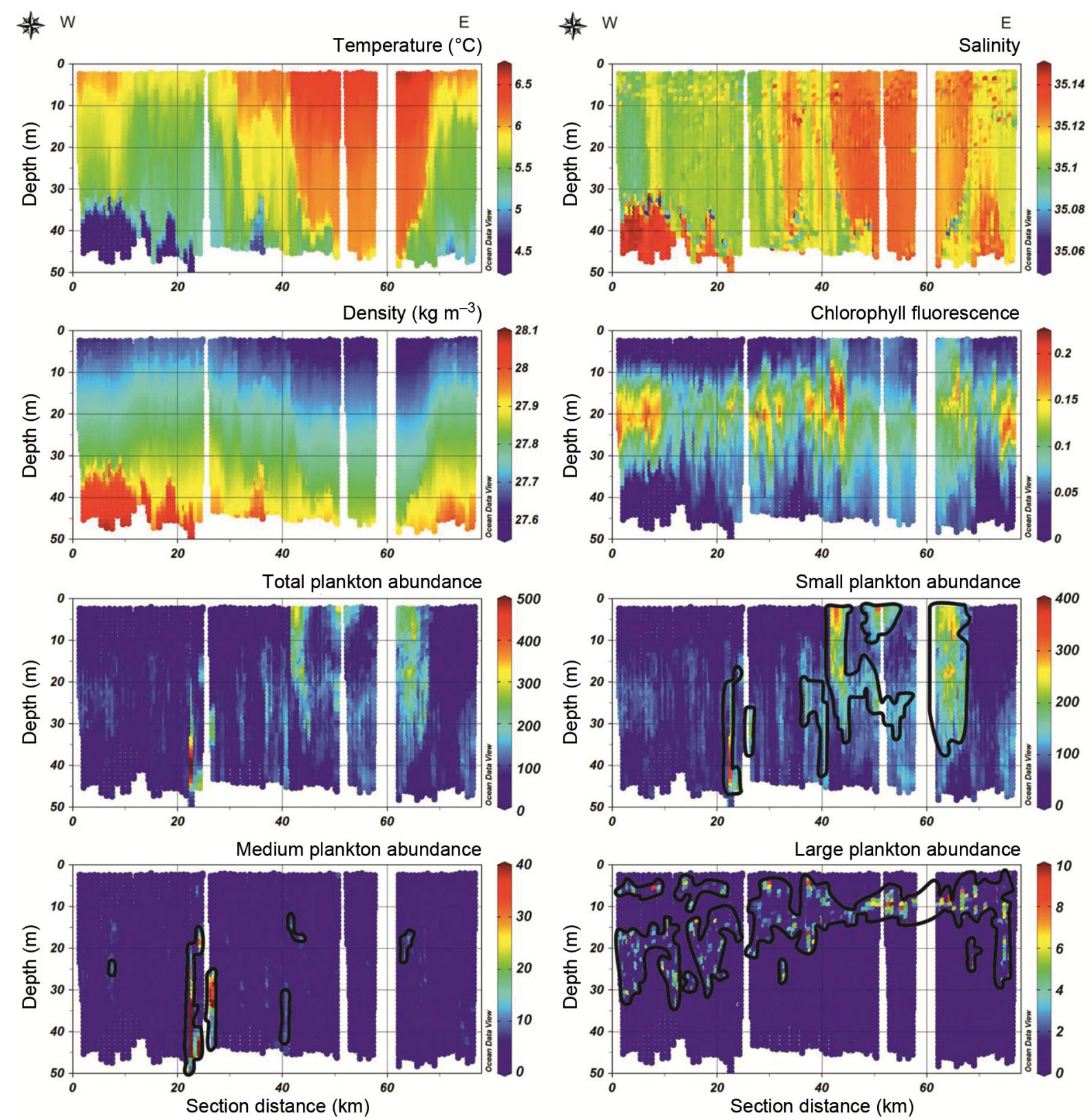

Fig. 6. West Spitsbergen Current (WSC) offshore section. Distribution of temperature, salinity, density, chlorophyll fluorescence and plankton abundance (ind. $\mathrm{m}^{-3} \times 10^{3}$ ) of total, small, medium and large size fractions along the section. The identified patches are outlined by solid black lines

large size fraction abundance and environmental variables in both WSC survey sections were the least pronounced.

\section{Species composition}

The results of the net sampling indicated that the zooplankton were very abundant in the SC section
(Table 4) and consisted mainly of calanoid copepods (Calanus glacialis, C. finmarchicus and Pseudocalanus spp.) and copepod nauplii. The copepods were found predominantly in the lower part of the studied layer, below $20 \mathrm{~m}$. The zooplankton of the SC also included another calanoid copepod, Acartia longiremis, as well as the ctenophore Mertensia ovum, the appendicularian Fritillaria borealis and the chaetognath Parasagitta elegans. 
Table 3. Non-parametric Spearman's rank-order correlations testing the pairwise relationships between vertically averaged particle and plankton abundances in the selected size categories (small, medium and large) and environmental variables (temperature, salinity, density, chlorophyll fluorescence)

\begin{tabular}{|lrrrrrrr|}
\hline Section & \multicolumn{2}{c}{ Small } & \multicolumn{2}{c}{ Medium } & \multicolumn{2}{c}{ Large } \\
& $\mathrm{R}$ & $\mathrm{p}$ & $\mathrm{R}$ & $\mathrm{p}$ & $\mathrm{R}$ & $\mathrm{p}$ \\
\hline & & & & & & \\
FZ (n = 85) & & & & & & \\
Temperature & 0.70 & $<0.001$ & 0.82 & $<0.001$ & 0.63 & $<0.001$ \\
Salinity & 0.83 & $<0.001$ & 0.80 & $<0.001$ & 0.48 & $<0.001$ \\
Density & 0.84 & $<0.001$ & 0.75 & $<0.001$ & 0.35 & 0.001 \\
Chlorophyll & 0.62 & $<0.001$ & 0.69 & $<0.001$ & 0.43 & $<0.001$ \\
SC (n = 25) & & & & & & \\
Temperature & -0.84 & $<0.001$ & -0.67 & $<0.001$ & -0.84 & $<0.001$ \\
Salinity & -0.17 & 0.414 & -0.36 & 0.080 & -0.14 & 0.495 \\
Density & 0.74 & $<0.001$ & 0.44 & 0.028 & 0.76 & $<0.001$ \\
Chlorophyll & 0.62 & 0.001 & 0.35 & 0.086 & 0.60 & 0.001 \\
WSC slope (n = 77) & & & & & & \\
Temperature & 0.62 & $<0.001$ & 0.36 & 0.001 & -0.01 & 0.904 \\
Salinity & -0.66 & $<0.001$ & -0.60 & $<0.001$ & -0.53 & $<0.001$ \\
Density & -0.91 & $<0.001$ & -0.61 & $<0.001$ & -0.27 & 0.019 \\
Chlorophyll & 0.86 & $<0.001$ & 0.63 & $<0.001$ & 0.28 & 0.015 \\
WSC offshore (n $=\mathbf{1 5 3 )}$ & & & & & \\
Temperature & 0.72 & $<0.001$ & -0.03 & 0.724 & -0.20 & 0.012 \\
Salinity & 0.50 & $<0.001$ & -0.29 & $<0.001$ & -0.28 & $<0.001$ \\
Density & -0.76 & $<0.001$ & -0.02 & 0.841 & 0.18 & 0.024 \\
Chlorophyll & 0.57 & $<0.001$ & 0.54 & $<0.001$ & 0.10 & 0.215 \\
& & & & & & & \\
\hline
\end{tabular}

namic region of the Polar Front. Through high-resolution measurements, it was possible to detect particles and plankton patches concurrently with the environmental conditions under which they occurred. The distinguished patches differed in terms of their number, extent, spatial distribution, particle and plankton concentration as well as their relationships to the structured physical environment.

The earliest investigations of zooplankton patchiness assumed that zooplankton patches are circular (Wiebe 1970), but most of the latest investigations have shown that they are rather elongated structures, i.e. are much longer in the horizontal than in the vertical dimension. Most of the patches found in our study were a few kilometres long horizontally, which is in agreement with the results of an earlier study on the WSS (Trudnowska et al. 2012) as well as with a study in the Mediterranean Sea (Molinero et al. 2008) that investigated the size of Calanus and Oithona patches (6 and $12 \mathrm{~km}$, respec-

The net zooplankton in the WSC slope section were more abundant in the eastern part (station N3P) than in the western part (station N2), where zooplankton were dominated by the cyclopoid copepod Oithona similis, younger life stages of C. finmarchicus and copepod nauplii. In the western part of this section, older life stages of $C$. finmarchicus were more abundant.

The zooplankton in the WSC offshore section were more abundant in the western part (N-2) and consisted mainly of $O$. similis and all developmental stages of $C$. finmarchicus. In the eastern part of the WSC offshore section (N1), the predominant zooplankton included older life stages of $C$. finmarchicus in the upper layer and $O$. similis in the lower layer (Table 4). Furthermore, in this section, the contribution of less-numerous taxa such as C. glacialis, Triconia spp. and meroplankton (e.g. Echinodermata and Bivalvia larvae) decreased compared with in the WSC slope section, whereas the contribution of Pseudocalanus spp. increased.

\section{DISCUSSION}

The present study contributes to the research on summer plankton distribution patterns in the dy- tively). According to Pinca \& Huntley (2000), patches of this size are considered small. However, Vogedes et al. (2014) found that in Svalbard fjord the zooplankton patches can be even smaller $(1.2 \mathrm{~km})$. In contrast, patches of large size are known to spread horizontally over many kilometres, that is between 30 and $60 \mathrm{~km}$ (Huntley et al. 1995) or even $>100 \mathrm{~km}$ in case of the largest patches (Pinca \& Huntley 2000). Patches of $C$. finmarchicus along the New England coast occupied $2500 \mathrm{~km}^{2}$ (Wishner et al. 1988). The vertical extension of the patches observed in the present study, from 5 to approximately $50 \mathrm{~m}$ (the entire studied water column), was within the typical range of regular patches (Pinca \& Huntley 2000), but much greater than typical patch thicknesses recorded for thin plankton layers (Dekshenieks et al. 2001, Benoit-Bird et al. 2009). The size of plankton patches and their variability generally scale inversely with the organism's size (Levin 1992), and because the swimming capability of zooplankton is directly proportional to its size (Pearre 1979), the size-fractionated approach to the analysis of particles and plankton patches was applied in the present study. However, the variability and size of the patches observed generally did not differ among various size fractions. Instead, the hypothesis proposed for this 

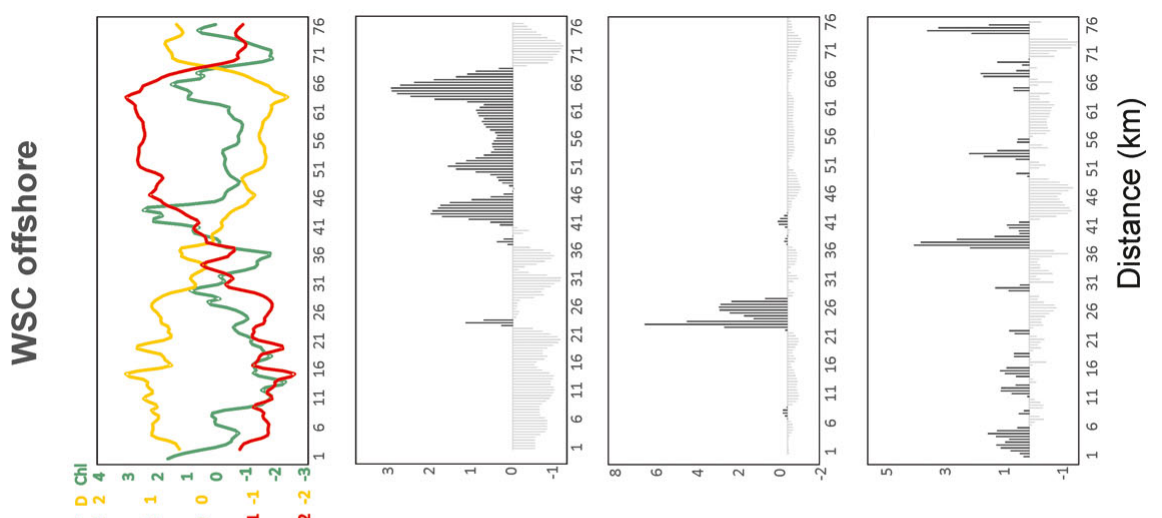

घี

$\circ . \exists$
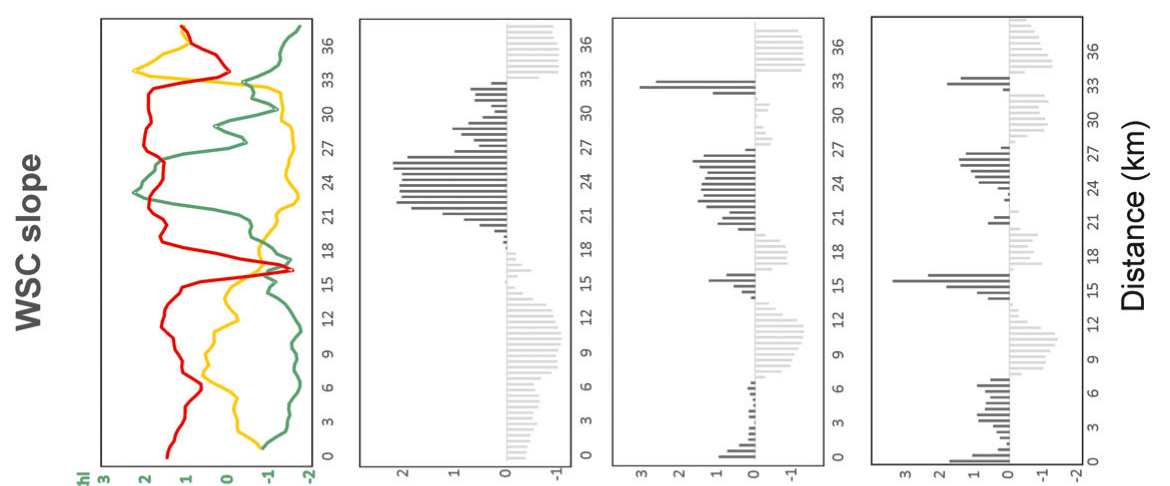

$\infty$

急

必寻

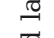

원 क्

ลิ)

ज्ञ त्र

घี 융 जै

$\infty$ o 3

i U U

象范

g]

ㅋ․ㄱ․

들을

की

피 बै

氙过

菏它

중크

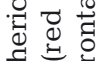
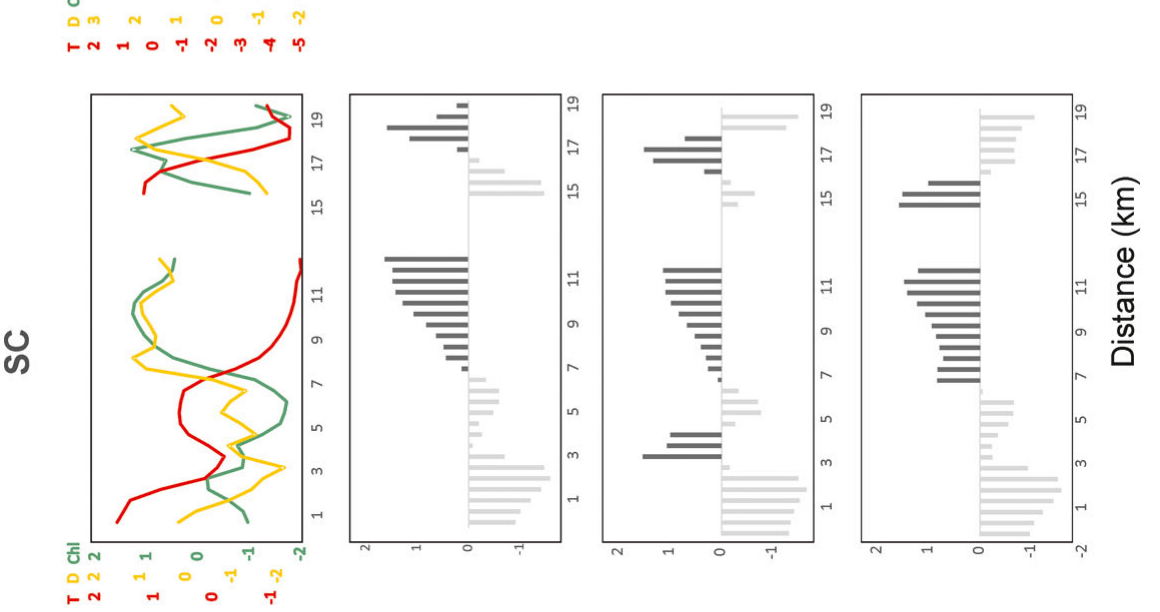

品品

记

录范䨌

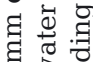

ก 3

i. 5

몽 월

न

हू प्र त्ठ

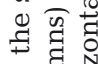

녈

ठ ठ

증

형 ?

तै द्वे है
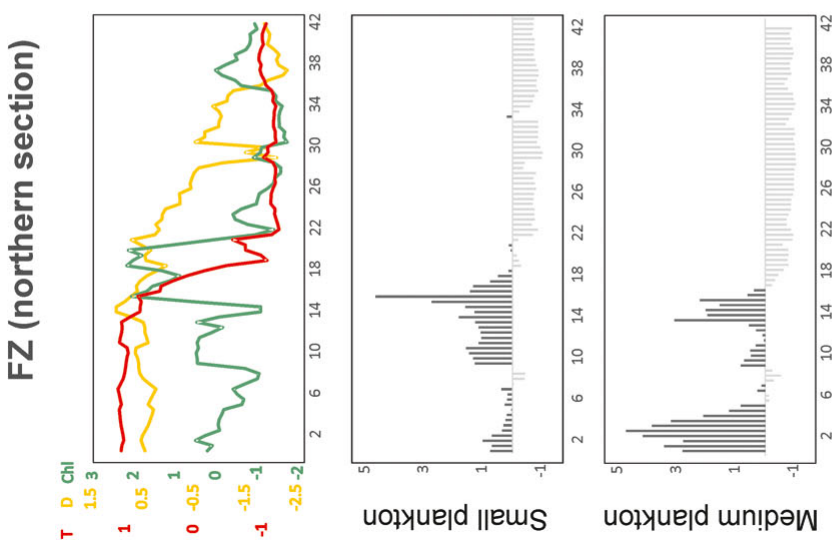

덜 궁

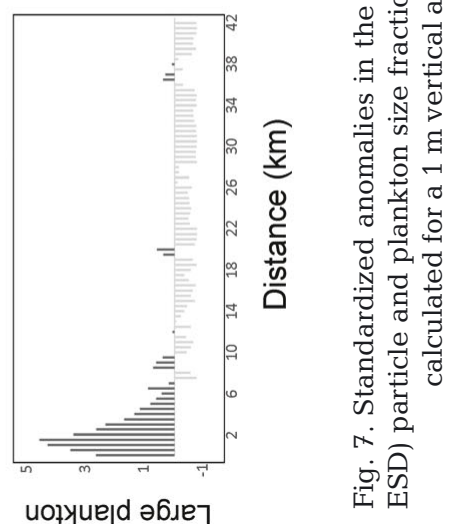

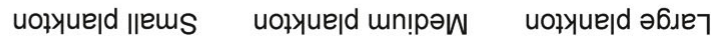


Table 4. Taxonomic composition of net zooplankton (abundance ind. $\mathrm{m}^{-3}$ )

\begin{tabular}{|c|c|c|c|c|c|c|c|c|c|c|c|c|}
\hline \multirow[t]{3}{*}{ Taxon } & \multicolumn{4}{|c|}{$\longrightarrow \mathrm{SC} \longrightarrow$} & \multicolumn{4}{|c|}{ WSC slope } & \multicolumn{4}{|c|}{ - WSC offshore - } \\
\hline & \multicolumn{2}{|c|}{ Stn V36 } & \multicolumn{2}{|c|}{ Stn V37 } & \multicolumn{2}{|c|}{ Stn N3P } & \multicolumn{2}{|c|}{ Stn N2 } & \multicolumn{2}{|c|}{ Stn N1 } & \multicolumn{2}{|c|}{ Stn N-2 } \\
\hline & $45-20 \mathrm{~m}$ & $20-0 \mathrm{~m}$ & $50-20 \mathrm{~m}$ & $20-0 \mathrm{~m}$ & $50-25 m$ & $25-0 \mathrm{~m}$ & $50-25 \mathrm{~m}$ & $25-0 \mathrm{~m}$ & $50-25 \mathrm{~m}$ & $25-0 \mathrm{~m}$ & $50-25 \mathrm{~m}$ & $25-0 \mathrm{~m}$ \\
\hline Calanus finmarchicus I-III & 115 & 104 & 147 & 94 & 251 & 552 & 67 & 4 & 83 & 36 & 219 & 447 \\
\hline C. finmarchicus CIV-CVI & 19 & 11 & 12 & 18 & 48 & 413 & 875 & 715 & 34 & 333 & 82 & 428 \\
\hline C. glacialis I-III & 2456 & 1063 & 3204 & 1903 & 13 & 26 & 0 & 1 & 2 & 1 & 0 & 0 \\
\hline C. glacialis CIV-CVI & 56 & 189 & 162 & 269 & 18 & 66 & 13 & 49 & 0 & 40 & 2 & 83 \\
\hline Pseudocalanus spp. CI-CIII & 176 & 85 & 557 & 263 & 5 & 3 & 6 & 2 & 9 & 0 & 5 & 1 \\
\hline Pseudocalanus spp. CV-CVIF & 19 & 24 & 109 & 47 & 17 & 3 & 21 & 5 & 33 & 6 & 38 & 53 \\
\hline Acartia longiremis & 3 & 31 & 6 & 66 & 0 & 0 & 0 & 0 & 0 & 0 & 0 & 0 \\
\hline Oithona similis & 80 & 73 & 239 & 153 & 1669 & 903 & 417 & 60 & 1086 & 122 & 1268 & 708 \\
\hline Copepoda nauplii & 624 & 740 & 1055 & 862 & 162 & 279 & 46 & 7 & 52 & 27 & 75 & 100 \\
\hline Triconia spp. & 0 & 2 & 5 & 0 & 57 & 8 & 11 & 12 & 4 & 4 & 2 & 6 \\
\hline Meroplankton & 51 & 50 & 133 & 235 & 30 & 32 & 9 & 33 & 5 & 4 & 1 & 3 \\
\hline Mertensia ovum & 6 & 10 & 7 & 77 & 0 & 0 & 0 & 0 & 0 & 0 & 0 & 0 \\
\hline Eukrohnia hamata & 0 & 0 & 0 & 2 & 17 & 2 & 25 & 1 & 36 & 3 & 55 & 5 \\
\hline Parasagitta elegans & 1 & 3 & 13 & 18 & 0 & 0 & 0 & 0 & 0 & 0 & 0 & 0 \\
\hline Appendicularia & 32 & 46 & 10 & 51 & 5 & 7 & 0 & 0 & 0 & 0 & 0 & 1 \\
\hline Others & 38 & 55 & 78 & 312 & 14 & 27 & 20 & 16 & 44 & 33 & 27 & 37 \\
\hline Total & 3675 & 2485 & 5738 & 4370 & 2305 & 2322 & 1509 & 906 & 1389 & 610 & 1775 & 1871 \\
\hline
\end{tabular}

study was supported by the tendency for the patches of smaller size particles and plankton to have a stronger relationship to the controlling physical conditions.

The method of averaged abundance and biomass over an area or a part of the water column (arbitrarily defined gridding) often fails to recognize the existence of plankton patches. This can only be achieved by high-resolution measurements of abundance or biomass rates of change over space (Benoit-Bird et al. 2009) or time, because the plankton patches occupy only a minor part of the ocean $(2-17 \%$ in the present study; $\sim 12 \%$ in the NE Pacific, Menden-Deuer 2012; 2-29\% in Monterey Bay, Benoit-Bird et al. 2009). However, the importance of patches results from the fact that the concentrations of plankton and particles in patches are generally a few times higher than in the background waters (3-17 orders higher in the present study). Such high plankton concentrations, compared to those in the surrounding water, were observed in earlier studies in thin plankton layers consisting of phytoplankton, bacteria, marine snow and zooplankton (Dekshenieks et al. 2001, Alldredge et al. 2002, Benoit-Bird et al. 2010).

The LOPC detects and counts all objects suspended in the sampled water volume. Most of the particle counts include biological elements (phytoplankton, zooplankton, faecal pellets), but may also incorporate inorganic suspended matter from a river (Schultes \& Lopes 2009) or a glacier plume (Trudnowska et al. 2014). Such material can constitute a substantial part of the counts and it may also have contributed to the composition of the small size fraction patch detected above the sea bottom in the shallow part of the SC section (Fig. 3). Supporting evidence for this conclusion may be that this patch, unlike other patches of the small size fraction, was not associated with detectable chlorophyll fluorescence. The high abundance of particles in this patch most probably consisted mainly of sea-bottom sediments resuspended by storm-induced wave action over a shallow part of the shelf or of terrigenous material brought into the sea by terrestrial or glacial freshwater run-off (Trudnowska et al. 2015). Differentiation of the relative composition of phytoplankton and detritus in oceanic suspended matter can be confirmed by the simultaneous measurement of the light-scattering and absorption characteristics of the particles (Stramski et al. 2001, Trudnowska et al. 2015), although these techniques were not available for the present survey.

One of the possible mechanisms of patch formation may be related to the existence of local areas of higher primary production or standing stock, resulting in a subsequent concentration of potential grazers (e.g. Basedow et al. 2006, Norrbin et al. 2009, MendenDeuer 2012). Indeed, the distribution of particles and plankton patches in the present study was often correlated with chlorophyll fluorescence maxima, as has been similarly demonstrated by, for example, BenoitBird \& McManus (2012). The high, positive correlation between chlorophyll fluorescence and the abundance 
of the small size fraction, especially in the WSC slope section, implies that a substantial part of the patch found there could comprise phytoplankton cells (Fig. 4, Table 3).

Particles and plankton are also known to concentrate and/or gather at density gradients (Woodson et al. 2005, Prairie et al. 2012). Patches of the medium size fraction taxa that are predominant in the study region (e.g. Oithona, Triconia, Acartia, young Pseudocalanus, copepod nauplii, benthic larvae) were frequently found concomitant with density discontinuities, such as the horizontal density gradient on the hydrographic front, the vertical density gradient at the pycnocline or the density gradients at the boundaries of pockets of hydrographically different waters. The density gradients may act as a barrier to particle and copepod movement and may facilitate the maintenance of their position near preferred habitats. Gallager et al. (2004) have shown that Calanus copepods occur in high numbers on the fringes of hydrographic gradients, as was also observed in the present study in the WSC slope section (large size fraction; see Figs. 4 \& 7).

It is possible that the formation of the large size fraction patches, the distribution of which was not clearly associated with any detected oceanographic feature, could result from the migratory capabilities of the zooplankton due to habitat selection, forced by ontogenetic, diel and foraging migrations as well as predator avoidance (Falkenhaug et al. 1997, Folt \& Burns 1999, Ambler 2002, Prairie et al. 2012). The biological cues could partly be modified by a lack of synchrony in daily vertical migrations, most likely present during midnight sun conditions (June-July). Previous studies either from the beginning (Blachowiak-Samolyk et al. 2006) or the end (Berge et al. 2014) of the productive season have indicated that vertical migration is not performed or is weakly pronounced in majority of the mesozooplankton taxa in the study region. The results of collecting zooplankton in the study area by nets suggest that the patches of the large size fraction consisted mainly of C. finmarchicus and C. glacialis, distribution of which also exhibited no evidence of dependence on environmental cues over small spatial scales in the northern North Sea (Solow \& Steele 1995).

The large size fraction patch in the WSC slope section, which could be attributed to elevated concentrations of $C$. finmarchicus, was located at the periphery of the intrusion of low salinity and cold water at the edge of the anticyclonic eddy. Eddylike mesoscale structures are commonly observed in
WSC waters (Gascard et al. 1995, Walczowski 2013), and peak zooplankton abundances are often found inside or on the peripheries of eddies (Riandey et al. 2005, Labat et al. 2009, Godø et al. 2012, Samuelsen et al. 2012). The high-resolution sections in the present study did not extend deep enough to detect the structure of the eddy; however, the analysis of fulldepth hydrographic point measurements, carried out in parallel to the continuous survey, confirmed the occurrence of a mesoscale anticyclonic baroclinic eddy, extending down to approximately $700 \mathrm{~m}$ (WSC slope section). Eddies can extend to depths greater than $500 \mathrm{~m}$ (Smith 1988), but the most pronounced contrasts in temperature are mostly found in the upper $25-50 \mathrm{~m}$, as in cyclonic eddies in the Fram Strait (Johannessen et al. 1987). The eddy observed in the present survey reached a diameter of approximately $30 \mathrm{~km}$, which is a typical size for mesoscale eddies in the Fram Strait (Walczowski 2013), where the Rossby radius of deformation is on the order of 10 $\mathrm{km}$. Eddies larger than the Rossby radius have an aggregating effect when rotating anticyclonically and a dispersive effect under cyclonic rotation. The aggregating effect of the anticyclonic rotation was confirmed in the present study, because the detected eddy contained extremely high particle and plankton concentrations. This eddy had a warm and salty core, similar to a $15-\mathrm{km}$-wide eddy that was previously observed near the surface in the vicinity of the Polar Front in the Barents Sea (Våge et al. 2014). A mesoscale eddy of this kind was also found over the continental slope of the northern Chukchi Shelf (Llinas et al. 2009). The eddy had a radius of $8 \mathrm{~km}$ and was associated with elevated concentrations of zooplankton, represented mainly by $C$. glacialis and M. longa. The aggregation of C. glacialis due to anticyclonic eddy circulation has also been observed in Academy Bay in the Sea of Okhotsk (Rogachev et al. 2008). Another eddy-like structure, with a cold-water core, was observed in the southern FZ sections. It was located at nearly the same location as a similar structure, containing almost exclusively the large copepod C. glacialis, that was found the previous year by Jakubas et al. (2013), which suggests a repeatable tendency for eddy formation in this region.

The Polar Front is a critical climatic feature for the dynamics of the Arctic region. To date, most studies of this feature have focused on the Barents Sea region (e.g. Loeng 1991, Parsons et al. 1996, Våge et al. 2014) while, in contrast, the Polar Front west of Spitsbergen has received substantial attention only recently. The recent studies reflect the understanding of the role of the Polar Front in modifying the heat 
exchange by the WSC and in controlling environmental conditions in the Spitsbergen fjords (Saloranta \& Svendsen 2001, Tverberg \& Nøst 2009, Walczowski 2013). Increased productivity of plankton autotrophs and zooplankton in frontal systems, manifested by their elevated abundance, is a well-documented phenomenon (Franks 1992, Molinero et al. 2008, Schultes et al. 2013). Observations in the FZ sections of the present study, showed elevated densities of various plankton size fractions in relation to the front line and are in agreement with other in situ data obtained in the Polar Front region of the Barents Sea (Basedow et al. 2010, 2014). Similar increases in concentrations of phytoplankton and zooplankton have been detected in association with a front over a narrow continental shelf off northern Norway (Skarðhamar et al. 2007) and also in the Gulf of Maine (Beardsley et al. 1996). Such peak concentrations of particles and plankton at fronts often persist in the form of convex doming structures (Molinero et al. 2008, Trudnowska et al. 2012).

Physical features in the form of fronts or eddies create attractive feeding habitats for higher trophic levels (e.g. Bakun 2006, Godø et al. 2012). For the WSS, the importance of the Arctic side of the Polar Front as the main foraging site for the little auk Alle alle has been recorded by Stempniewicz et al. (2007) and Kwasniewski et al. (2010). The results of at-sea bird tracking studies showed that birds are able to sight the patches of potential prey and intensify foraging in these regions (WSS, Jakubas et al. 2013; Fram Strait, Joiris \& Falck 2011). The higher overall particle and plankton abundances in the Atlantic offshore waters, in comparison to the Arctic waters on the shelf, are consistent with the results of previous studies in the frontal zone on the WSS (e.g. Kwasniewski et al. 2010, Dvoretsky \& Dvoretsky 2013, Jakubas et al. 2013). In contrast, which fish components of the marine food web (e.g. capelin Molotus villosus, herring Clupea herrengus, possibly also Atlantic cod Gadus morhua or haddock Melanogramus aeglefinus) take advantage of higher concentrations of plankton on the Atlantic side of the Polar Front in the WSS region is still to be confirmed from direct observations. The results of the present investigation highlight the link between environmental gradients and the distribution of microhabitats in the Polar Front area in the vicinity of Spitsbergen. In turn, the differentiation of the pelagic habitat has consequences for ecosystem structure and functioning, due to its direct impact on spatial species distribution and trophic interactions.

\section{CONCLUSIONS}

This study highlights the mosaic nature of the distribution pattern of particles and plankton, as well as its response to a structured environment. It shows that the generation and existence of patches could be associated with peculiar conditions created by increased primary production, optimal hydrography, discontinuities in the density field and/or the presence of meanders or eddies.

The distribution of the small size fraction patches, comprising either phytoplankton (WSC sections) or non-living particles (SC section), was closely related to specific patterns in hydrography. The patches of the medium size fractions, consisting of small zooplankton and marine snow, concentrated predominately at discontinuities in density field. The distribution of the large size fraction patches, which comprised mostly Calanus copepods, was not associated with any specific hydrographic or hydrodynamic feature detected in this study and it is thus assumed that biological factors were the major causes responsible for their migration and aggregation processes.

The observations on different relationships between the environmental structures and diverse, size-specific particle and plankton distribution patterns provide new data for discussions about the concepts of marine ecosystem structure and functioning. However, several aspects remain to be studied, such as patch persistence, details of patch composition and origin, and their ecological consequences. Recently improved ability to observe patches of plankton with increased resolution, owing to the application of acoustic and optical methods, should further facilitate studies enabling a comprehensive understanding and explanation of the spatial and temporal variability of plankton distribution under the dynamic conditions of the Arctic Ocean. These investigations will require synchronised measurements and sampling using these modern and advanced in situ optical and acoustical sensors, together with satellite observations to allow proper spatial and/or temporal resolution of the investigations.

Acknowledgements. The authors acknowledge the Captain and crew of the RV 'Oceania' for their valuable support during field measurements. This study was supported by the Polish Scientific Council, project KongHau_ZOOM (2375/ Svalbard/2012/2, Nr W37/Svalbard/2012), and partly by a grant under the Polish-Norwegian Research Programme, project PAVE, contract no POL-NOR/202006/10/2013. 


\section{LITERATURE CITED}

Alldredge $\mathrm{AL}$, Cowles $\mathrm{TJ}$, MacIntyre $\mathrm{S}$, Rines JEB and others (2002) Occurrence and mechanisms of formation of a dramatic thin layer of marine snow in a shallow Pacific fjord. Mar Ecol Prog Ser 233:1-12

Ambler JW (2002) Zooplankton swarms: characteristics, proximal cues and proposed advantages. Hydrobiologia 480:155-164

Bakun A (2006) Fronts and eddies as key structures in the habitat of marine fish larvae: opportunity, adaptive response and competitive advantage. Sci Mar 70S2: 105-122

Basedow SL, Edvardsen A, Tande K (2006) Spatial patterns of surface blooms and recruitment dynamics of Calanus finmarchicus in the NE Norwegian Sea. J Plankton Res 28:1181-1190

Basedow SL, Zhou M, Tande KS (2010) Biovolume spectrum theories applied: spatial patterns of trophic levels within a mesozooplankton community at the Polar Front. J Plankton Res 32:1105-1119

Basedow SL, Zhou M, Tande KS (2014) Secondary production at the Polar Front, Barents Sea, August 2007. J Mar Syst 130:147-159

Beardsley RC, Epstein AW, Chen C, Wishner KF, Macaulay MC, Kenney RD (1996) Spatial variability in zooplankton abundance near feeding right whales in the Great South Channel. Deep-Sea Res II 43:1601-1625

Benfield MC, Davis CS, Wiebe PH, Gallager SM, Lough RG, Copley NJ (1996) Video plankton recorder estimates of copepod, pteropod and larvacean distributions from a stratified region of Georges Bank with comparative measurements from a MOCNESS sampler. Deep-Sea Res II 43:1925-1945

Benoit-Bird KJ, McManus MA (2012) Bottom-up regulation of a pelagic community through spatial aggregations. Biol Lett 8:813-816

> Benoit-Bird KJ, Cowles TJ, Wingard CH (2009) Edge gradients provide evidence of ecological interactions in planktonic thin layers. Limnol Oceanogr 54:1382-1392

- Benoit-Bird KJ, Moline MA, Waluk ChM, Robbins IC (2010) Integrated measurements of acoustical and optical thin layers I: Vertical scales of association. Cont Shelf Res 30: $17-28$

Berge J, Cottier F, Varpe $\varnothing$, Renaud PE and others (2014) Arctic complexity: a case study on diel vertical migration of zooplankton. J Plankton Res 36:1279-1297

> Beszczyńska-Möller A, Fahrbach E, Schauer U, Hansen E (2012) Variability in Atlantic water temperature and transport at the entrance to the Arctic Ocean, 1997-2010. ICES J Mar Sci 69:852-863

Blachowiak-Samolyk K, Kwasniewski S, Richardson K, Dmoch K and others (2006) Arctic zooplankton do not perform diel vertical migration (DVM) during periods of midnight sun. Mar Ecol Prog Ser 308:101-116

> Cowles TJ, Desiderio RA (1998) Small-scale planktonic structure: persistence and trophic consequences. Oceanography 11:4-9

d'Ovidio F, De Monte S, Alvain S, Dandonneau Y, Lęvy M (2010) Fluid dynamical niches of phytoplankton types. Proc Natl Acad Sci USA 107:18366-18370

Dagg MJ (1977) Some effects of patchy food environments on copepods. Limnol Oceanogr 22:99-107

> Davis CS, Hu Q, Gallager SM, Tang X, Ashjian CJ (2004) Real-time observation of taxa-specific plankton distribu- tions: an optical sampling method. Mar Ecol Prog Ser 284:77-96

Dekshenieks MM, Donaghay PL, Sullivan JM, Rines JEB, Osborn TR, Twardowski MS (2001) Temporal and spatial occurrence of thin phytoplankton layers in relation to physical processes. Mar Ecol Prog Ser 223:61-71

Deutschman DH, Bradshaw GA, Childress WM, Daly K and others (1993) Mechanisms of patch formation. In: Levin S, Powell T, Steel J (eds) Patch dynamics. Springer, Berlin, p 184-209

Dormann CF, McPherson JM, Araujo MB, Bivand R and others (2007) Methods to account for spatial autocorrelation in the analysis of species distributional data: a review. Ecography 30:609-628

> Dvoretsky VG, Dvoretsky AG (2013) Structure of mesozooplankton community in the Barents Sea and adjacent waters in August 2009. J Nat Hist 47:2095-2114

Falkenhaug T, Tande KS, Semenova T (1997) Diel, seasonal and ontogenetic variations in the vertical distributions of four marine copepods. Mar Ecol Prog Ser 149:105-119

Folt CL, Burns CW (1999) Biological drivers of zooplankton patchiness. Trends Ecol Evol 14:300-305

> Franks PJS (1992) Sink or swim: accumulation of biomass at fronts. Mar Ecol Prog Ser 82:1-12

Franks PJS (2005) Plankton patchiness, turbulent transport and spatial spectra. Mar Ecol Prog Ser 294:295-309

> Gallager SM, Yamazaki H, Davis CS (2004) Contribution of fine-scale vertical structure and swimming behavior to formation of plankton layers on Georges Bank. Mar Ecol Prog Ser 267:27-43

Gascard JC, Richez C, Roaualt C (1995) New insights on large-scale oceanography in Fram Strait: the West Spitsbergen Current. In: Smith WO Jr, Grebmeier JM (eds) Arctic oceanography: marginal ice zones and continental shelves. AGU 49, Washington, DC, p 131-182

Genin A, Jaffe JS, Reef R, Richter C, Franks PJS (2005) Swimming against the flow: a mechanism of zooplankton aggregation. Science 308:860-862

George DG (1981) Zooplankton patchiness. Rep Freshw Biol Assoc UK 49:32-44

Godø OR, Samuelsen A, Macaulay GJ, Patel R and others (2012) Mesoscale eddies are oases for higher trophic marine life. PLOS ONE 7:e30161

Haarpaintner J, Gascard JC, Haugan PM (2001) Ice production and brine formation in Storfjorden, Svalbard. J Geophys Res 106:14001-14013

Haury LR, McGowan JA, Wiebe PH (1978) Patterns and processes in the time-space scales of plankton distributions. In: Steele JH (ed) Spatial pattern in plankton communities. Plenum Press, New York, NY, p 277-326

- Herman AW, Beanlands B, Phillips EF (2004) The next generation of Optical Plankton Counter: The Laser-OPC. J Plankton Res 26:1135-1145

Huntley M, Zhou M, Nordhausen W (1995) Mesoscale distribution of zooplankton in the California Current in late spring, observed by Optical Plankton Counter. J Mar Res 53:647-674

> Jakubas D, Trudnowska E, Wojczulanis-Jakubas K, Iliszko L and others (2013) Foraging closer to the colony leads to faster growth in little auks. Mar Ecol Prog Ser 489: 263-278

Johannessen JA, Johannessen OM, Svendsen E, Shuchman $\mathrm{R}$ and others (1987) Mesoscale eddies in the Fram Strait marginal ice zone during the 1983 and 1984 Marginal Ice Zone Experiments. J Geophys Res 92:6754-6772 
Joiris CR, Falck E (2011) Summer at-sea distribution of little auks Alle alle and harp seals Pagophilus (Phoca) groenlandica in the Fram Strait and the Greenland Sea: impact of small-scale hydrological events. Polar Biol 34:541-548

- Kaltenberg AM, Benoit-Bird KJ (2013) Intra-patch clustering in mysid swarms revealed through multifrequency acoustics. ICES J Mar Sci 70:883-891

- Kwasniewski S, Hop H, Falk-Petersen S, Pedersen G (2003) Distribution of Calanus species in Kongsfjorden, a glacial fjord in Svalbard. J Plankton Res 25:1-20

Kwasniewski S, Gluchowska M, Jakubas D, WojczulanisJakubas K and others (2010) The impact of different hydrographic conditions and zooplankton communities on provisioning little auks along the west coast of Spitsbergen. Prog Oceanogr 87:72-82

Labat JP, Gasparini S, Mousseau L, Prieur L, Boutoute M, Mayzaud P (2009) Mesoscale distribution of zooplankton biomass in the northeast Atlantic Ocean determined with an Optical Plankton Counter: relationships with environmental structures. Deep-Sea Res I 56:1742-1756

> Levin SA (1992) The problem of pattern and scale in ecology: the Robert H. MacArthur Award Lecture. Ecology 73:1943-1967

Llinas L, Pickart RS, Mathis JT, Smith SL (2009) Zooplankton inside an Arctic Ocean cold-core eddy: probable origin and fate. Deep-Sea Res II 56:1290-1304

> Loeng H (1991) Features of the physical oceanographic conditions in the central parts of the Barents Sea. Polar Res 10:5-18

> Majaneva S, Berge J, Renaud PE, Vader A and others (2013) Aggregations of predators and prey affect predation impact of the Arctic ctenophore Mertensia ovum. Mar Ecol Prog Ser 476:87-100

Mehlum F, Hunt G Jr, Klusek Z, Decker MB (1999) Scaledependent correlations between the abundance of Brünnich's guillemots and their prey. J Anim Ecol 68:60-72

Menden-Deuer S (2012) Structure-dependent phytoplankton photosynthesis and production rates: implications for the formation, maintenance, and decline of plankton patches. Mar Ecol Prog Ser 468:15-30

> Molinero JC, Ibanez F, Souissi S, Bosc E, Nival P (2008) Surface patterns of zooplankton spatial variability detected by high frequency sampling in the NW Mediterranean. Role of density fronts. J Mar Syst 69:271-282

Nilsen F, Gjevik B, Schauer U (2006) Cooling of the West Spitsbergen Current: isopycnal diffusion by topographic vorticity waves. J Geophys Res 111:C08012

> Norrbin F, Eilertsen HCh, Degerlund M (2009) Vertical distribution of primary producers and zooplankton grazers during different phases of the Arctic spring bloom. DeepSea Res II 56:1945-1958

> Omori M, Hamner WM (1982) Patchy distribution of zooplankton: behavior, population assessment and sampling problems. Mar Biol 72:193-200

> Parsons AR, Bourke RH, Muench RD, Chit CS, Lynch JF, Miller JH, Plueddemann AJ, Pawlowicz R (1996) The Barents Sea Polar Front in summer. J Geophys Res 101: 14201-14221

> Pearre S (1979) Problems of detection and interpretation of vertical migration. J Plankton Res 1:29-44

> Pinca S, Huntley ME (2000) Spatial organization of particle size composition in an eddy-jet system off California. Deep-Sea Res I 47:973-996

Pinel-Alloul P (1995) Spatial heterogeneity as a multiscale characteristic of zooplankton community. Hydrobiologia
300-301:17-42

Piontkovski SA, Williams R, Peterson WT, Yunev OA, Minkina NI, Vladimirov VL, Blinko A (1997) Spatial heterogeneity of the planktonic fields in the upper mixed layer of the open ocean. Mar Ecol Prog Ser 148:145-154

Postel L (2000) Biomass and abundance. In: Harris RP, Wiebe PH, Lenz J, Skjoldal HR, Huntley M (eds) ICES zooplankton methodology manual. Academic Press, London, p 83-192

> Prairie JC, Sutherland KR, Nickols KJ, Kaltenberg AM (2012) Biophysical interactions in the plankton: a crossscale review. Limnol Oceanogr Fluids Environ 2:121-145

> Riandey V, Champalbert G, Carlotti F, Taupier-Letage I, Thibault-Botha D (2005) Zooplankton distribution related to the hydrodynamic features in the Algerian Basin (western Mediterranean Sea) in summer 1997. Deep-Sea Res I 52:2029-2048

> Riley GA (1976) A model of plankton patchiness. Limnol Oceanogr 21:873-880

> Rogachev KA, Carmack EC, Foreman MGG (2008) Bowhead whales feed on plankton concentrated by estuarine and tidal currents in Academy Bay, Sea of Okhotsk. Cont Shelf Res 28:1811-1826

Saloranta TM, Haugan PM (2001) Interannual variability in the hydrography of Atlantic water northwest of Svalbard. J Geophys Res C Oceans 106:13931-13943

Saloranta TM, Svendsen H (2001) Across the Arctic front west of Spitsbergen: high-resolution CTD sections from 1998-2000. Polar Res 20:177-184

Samuelsen A, Hjøllo SS, Johannessen JA, Patel R (2012) Particle aggregation at the edges of anticyclonic eddies and implications for distribution of biomass. Ocean Sci 8: 389-400

Schlitzer R (2015) Ocean Data View. http://odv.awi.de

Schultes S, Lopes RM (2009) Laser Optical Plankton Counter and Zooscan intercomparison in tropical and subtropical marine ecosystems. Limnol Oceanogr Methods 7:771-784

Schultes S, Sourisseau M, Le Masson E, Lunven M, Marie L (2013) Influence of physical forcing on mesozooplankton communities at the Ushant tidal front. J Mar Syst 109-110:S191-S202

Skarðhamar J, Slagstad D, Edvardsen A (2007) Plankton distributions related to hydrography and circulation dynamics on a narrow continental shelf off Northern Norway. Estuar Coast Shelf Sci 75:381-392

> Skogseth R, Haugan PM, Jakobsson M (2005) Watermass transformations in Storfjorden. Cont Shelf Res 25:667-695

Smith FE (1972) Spatial heterogeneity, stability and diversity in ecosystems. Trans Conn Acad Arts Sci 44:309-335

$>$ Smith SL (1988) Copepods in Fram Strait in summer: distribution, feeding and metabolism. J Mar Res 46:145-181

Sokal RR, Rohlf FJ (1981) Introduction to biostatistics, 2nd edn. Island Press, Washington, DC

Solow AR, Steele JH (1995) Scales of plankton patchiness: biomass versus demography. J Plankton Res 17:1669-1677

Stempniewicz L, Błachowiak-Samołyk K, Wesławski JM (2007) Impact of climate change on zooplankton communities, seabird populations and arctic terrestrial ecosystem: a scenario. Deep-Sea Res II 54:2934-2945

Stramski D, Bricaud A, Morel A (2001) Modeling the inherent optical properties of the ocean based on the detailed composition of the planktonic community. Appl Opt 40: 2929-2945

Sullivan JM, Donaghay PL, Rines JEB (2010) Coastal thin 
layer dynamics: consequences to biology and optics. Cont Shelf Res 30:50-65

Teigen SH, Nilsen F, Gjevik B (2010) Barotropic Instability in the West Spitsbergen Current. J Geophys Res 115: C07016

Trudnowska E, Szczucka J, Hoppe L, Boehnke R, Hop H, Blachowiak-Samolyk K (2012) Multidimensional zooplankton observations on the northern West Spitsbergen Shelf. J Mar Syst 98-99:18-25

Trudnowska E, Basedow SL, Blachowiak-Samolyk K (2014) Mid-summer mesozooplankton biomass, its size distribution, and estimated production within a glacial Arctic fjord (Hornsund, Svalbard). J Mar Syst 137:55-66

Trudnowska E, Sagan S, Kwasniewski S, Darecki M, Blachowiak-Samolyk K (2015) Fine-scale zooplankton vertical distribution in relation to hydrographic and optical characteristics of the surface waters on the Arctic shelf. J Plankton Res 37:120-133

Tverberg V, Nøst OA (2009) Eddy overturning across a shelf edge front: Kongsfjorden, West Spitsbergen. J Geophys Res 114:C04024

Våge S, Basedow SL, Tande KS, Zhou M (2014) Physical structure of the Barents Sea Polar Front near Storbanken

Editorial responsibility: Graham Savidge,

Portaferry, UK in August 2007. J Mar Syst 130:256-262

> Vogedes D, Eiane K, Batnes AS, Berge J (2014) Variability in Calanus spp. abundance on fine- to mesoscales in an Arctic fjord: implications for little auk feeding. Mar Biol Res 10:437-448

Walczowski W (2013) Frontal structures in the West Spitsbergen Current margins. Ocean Sci 9:957-975

Walczowski W, Piechura J, Osinski R, Wieczorek P (2005) The West Spitsbergen Current volume and heat transport from synoptic observations in summer. Deep-Sea Res I 52:1374-1391

Wiebe PH (1970) Small-scale spatial distribution in oceanic zooplankton. Limnol Oceanogr 15:205-217

Wishner K, Durbin E, Durbin A, Macaulay M, Winn H, Kenney R (1988) Copepod patches and right whales in the great south channel off new England. Bull Mar Sci 43: 825-844

> Woodson CB, Webster DR, Weissburg MJ, Yen J (2005) Response of copepods to physical gradients associated with structure in the ocean. Limnol Oceanogr 50:1552-1564

Zhou M, Huntley M (1996) The principle of biological attraction, demonstrated by the bio-continuum theory of zooplankton patch dynamics. J Mar Res 54:1017-1037

Submitted: April 14, 2016; Accepted: October 5, 2016

Proofs received from author(s): November 14, 2016 